\title{
Laboreal
}

Volume $10 \mathrm{~N}^{\circ} 1$ | 2014

Análise ergonómica do trabalho e formação

\section{A “Didática psicológica. Aplicação à didática da psicologia de Jean Piaget" de Aebli : uma abordagem e um autor esquecidos}

La "Didáctica psicológica. Aplicación a la didáctica de la psicología de Jean

Piaget" de Aebli, un enfoque y un autor olvidados

La "Didactique psychologique. Application à la didactique de la psychologie de

Jean Piaget" de Aebli, une approche et un auteur oubliés

The "Psychological didactics. Application of the Jean Piaget psychology to the didactics", by Aebli; the forgotten approach of a forgotten author

Janine Rogalski

Tradutor. João Viana Jorge

\section{(2) OpenEdition}

Journals

Edição electrónica

URL: http://journals.openedition.org/laboreal/5445

DOI: $10.4000 /$ laboreal.5445

ISSN: 1646-5237

Editora

Universidade do Porto

Refêrencia eletrónica

Janine Rogalski, " A "Didática psicológica. Aplicação à didática da psicologia de Jean Piaget" de Aebli : uma abordagem e um autor esquecidos », Laboreal [Online], Volume $10 N^{0} 1$ | 2014, posto online no dia 01 julho 2014, consultado o 24 setembro 2020. URL : http://journals.openedition.org/laboreal/5445 ; DOl : https://doi.org/10.4000/laboreal.5445

Este documento foi criado de forma automática no dia 24 setembro 2020.

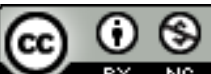

Laboreal está licenciado com uma Licença Creative Commons - Atribuição-NãoComercial 4.0 Internacional. 


\section{A “Didática psicológica. Aplicação à didática da psicologia de Jean Piaget" de Aebli : uma abordagem e um autor esquecidos}

La "Didáctica psicológica. Aplicación a la didáctica de la psicología de Jean

Piaget" de Aebli, un enfoque y un autor olvidados

La "Didactique psychologique. Application à la didactique de la psychologie de Jean Piaget" de Aebli, une approche et un auteur oubliés

The "Psychological didactics. Application of the Jean Piaget psychology to the didactics", by Aebli; the forgotten approach of a forgotten author

Janine Rogalski

Tradução : João Viana Jorge

\section{REFERÊNCIA}

Artigo original : Aebli, H. (1951). Didactique psychologique. Application à la didactique de la psychologie de Jean Piaget. Neuchâtel : Delachaux \& Niestlé.

\section{NOTA DO EDITOR}

http://dx.doi.org/10.15667/laborealx0114jr

1 As didáticas disciplinares e profissionais participam em conjunto com a ergonomia, a sociologia e a psicologia do trabalho, no desenvolvimento dos conhecimentos respeitantes à análise da actividade real em situação, na escola e no trabalho. Os investigadores nesse domínio, talvez por a constituição do seu campo de investigação 
ser recente explicitam mito raramente a origem das suas fontes. Neste artigo procuraremos reconstituir aquilo que devem a um investigador cujos trabalhos percursores são ignorados ou pouco conhecidos :

Hans Aebli (1923-1990).

Hans Aebli publica em 1951 a obra "Didactique psychologique. Application à la didactique de la psychologie de Jean Piaget" [1], no mesmo ano da defesa da sua tese sob a orientação de Piaget. Trata-se do seu primeiro livro e do único disponível em francês [ $\left.{ }^{2}\right]$. A característica original desta publicação é não só a de deduzir, da teoria psicológica de Piaget, uma didática mas também a de demostrar experimentalmente a eficácia dessa abordagem aplicada a um objecto de ensino da matemática.

Todavia, como sublinham Régis Ouvrier-Bonnaz e Marianne Lacomblez (2014), “quando os didactas vieram a interessar-se por Piaget, é a dimensão epistemológica que privilegiarão, sem (relayer) retomar os trabalhos de Aebli". O termo "relayer" parece-nos importante se compreendido como constatando que a obra de Aebli é na verdade muito citada em trabalhos franceses, tanto na pedagogia como na didática das matemáticas, contudo, o conteúdo propriamente dito da obra, é ignorado - com poucas exceções [3]. Daí que procuraremos compreender porque é que esta proposta, visando sustentar cada didática através da contribuição da teoria piagetiana, não teve uma influência imediata. A questão coloca-se particularmente na didática das matemáticas ; pelo menos um debate crítico teria podido ter sido iniciado a partir daí.

5 Para tratar dessa questão situaremos, em primeiro lugar, e rapidamente, a “ Didactique psychologique » na vida profissional de Aebli. Por um lado, voltaremos ao que é para ele a "didática" e como ele a situa em relação às ciências da educação e, por outro, teremos em vista o seu significado ulterior na didática das matemáticas. Após um balanço da sua crítica dos pressupostos psicológicos da "didática tradicional" e da sua crítica da " escola activa ", apresentaremos de seguida a démarche da elaboração, por Aebli, de um método didáctico a partir do quadro teórico de Piaget e as linhas de experimentação que apresenta para apoiar as suas propostas. Concluiremos com um ensaio de explicação para o facto do balanço que Aebli quis elaborar não ter desempenhado o papel de precursor que poderia ter sido o seu.

\section{A “Didática psicológica” na trajectória de Hans Aebli}

6 O conteúdo desta primeira obra de Aebli é inicialmente apoiado (escorado) pelas experiências conduzidas em contexto piagetiano. Apoia-se igualmente em conhecimentos experienciais de Aebli, professor primário. Piaget sublinha, no seu prefácio, a importância desta dupla qualificação de psicólogo e de educador para (daí) deduzir uma utilização didática dos trabalhos psicológicos. Acresce que no decurso do seu período de estudo em Minneapolis, no fim dos anos 40, Aebli “foi confrontado com a abordagem do pragmatismo americano por intermédio do filósofo da educação John Dewey" (documento web da fundação Näf Aebli : http://www.ans.ch/fr/). Os trabalhos ulteriores de Aebli virão a ser marcados por diversas características. Por um lado afastar-se-á do estrito quadro construtivista piagetiano (Aebli, 1978) na análise do desenvolvimento do pensamento da criança, particularmente ao introduzir a dimensão da interiorização dos conhecimentos, já conhecida do mestre. Assim, abrirá amplamente os seus trabalhos em direcção da análise do ensino e da formação dos docentes. Por outro lado publicará essencialmente em alemão (dada a sua pertença 
institucional [4]), e - infelizmente - nenhuma das suas obras terá sido traduzida para francês. A sua obra inicial tornar-se-á assim em França um "ponto isolado" da didática desenvolvida por Aebli, enquanto ela viria a ter uma posteridade bem estabelecida na Alemanha e na Suíça de língua alemã.

\section{A didática : ciência e método de ensino das disciplinas escolares}

7 Aebli definiu a didática como "uma ciência auxiliar da pedagogia na qual esta última delega para a realização de pormenor, as tarefas educativas mais gerais" (introdução, p.1). Define-lhe os alvos (os problemas): "qualquer didática deve definir [...] não apenas como os alunos "conhecem" determinada matéria [primeiro problema didáctico] mas também como a aprendem [segundo problema didáctico] [...]. À didática incumbe além disso estudar as condições mais favoráveis a estes processos de formação [terceiro problema didáctico]

Insiste (Aebli) na dimensão psicológica da didática e na sua ligação com uma psicologia : "qualquer método de ensino é solidário com uma psicologia da criança e do seu pensamento, frequentemente não explicitada", enquanto "a didática científica atribuise como tarefa deduzir do conhecimento psicológico dos processos de formação intelectual as medidas metodológicas mais aptas a provocá-la" (p. 2). Como lembra no preâmbulo : "só uma psicologia como a de Jean Piaget [...] pode fornecer os conceitos necessários para a solução de semelhantes problemas didácticos".

o singular do termo "didática" indica o caracter genérico do princípio piagetiano no cerne de "Didactique psychologique » : "pensar é operar". Todavia Aebli especifica que este princípio deve ser declinado segundo as diferentes disciplinas escolares e desenvolve-o para o caso das matemáticas (da escola primária).

\section{Da insuficiência da "didática tradicional" e do lugar da " psicologia tradicional » nos princípios da "escola activa" à psicologia piagetiana fundadora da "didática científica"}

A parte histórica da obra de Aebli (pp.5-37) defende desde do início que a "didática tradicional" se fundamenta no "princípio da intuição". Esta conceção "sensualistaempirista" [5] é sustentada por uma psicologia tradicional empirista, incapaz de dar conta mesmo da aquisição das imagens mentais. A "didática da escola ativa" é analisada através de obras de teorizadores "cujos trabalhos deram lugar a realizações práticas e que expuseram explicitamente a psicologia sobre a qual assenta a sua pedagogia".

11 À de W.A. Lay [6] falta uma conceção da natureza activa do pensamento, ainda que ele considere justamente a criança como "membro duma comunidade da qual sofre acções $e$ sobre a qual reage" (p. 21). Uma longa secção é dedicada a Dewey para discutir as didáticas baseadas numa "interpretação instrumentalista do pensamento" [7]. 0 pensamento é aí, decerto um utensílio, mas - critica Aebli - para além da análise da função do pensamento falta-lhe a questão da sua natureza intrínseca que a torna operatória. 


\section{Nos fundamentos da didática de Aebli : a psicologia piagetiana}

12 O cerne da obra (pp.39-106) é consagrado a explicitar como a didática pode/deve alimentar-se com a psicologia piagetiana. Nesta Parte psicológica (pp. 39-71), Aebli começa pela interpretação, por Piaget, da imagem mental como interiorização da acção, a qual se opõe à concepção da psicologia tradicional ; examina a seguir a actividade intelectual do aluno na escola tradicional do ponto de vista desta teoria da interiorização (L'image et l'opération, pp. 40-48). Continua desenvolvendo os conceitos de hábitos tais como podem ser adquiridos na escola tradicional inclusive quando relativos ao manuseamento dos símbolos e de operações (mentais), a (um) campo de aplicação mais amplo, formando sistemas de conjunto e cuja mobilidade - ligada à sua reversibilidade - se opõe à estereotipia do desenrolar dos hábitos (L'habitude et l'opération, pp. 49-60). Aebli consagra a seguir uma seç̧ão à relação entre a noção de operação e a cooperação dos alunos (p. 57 e seguintes). Desenvolve, com referência a Piaget, em que é que a cooperação social é um dos principais agentes formadores na génese espontânea do pensamento infantil e conclui pela "necessidade imperativa de o ensino moderno tirar partido desse facto destinando, nos programas escolares, um lugar importante às actividades socializadas".

13 Após o capítulo centrado nas relações entre operações e cooperação dos alunos, um outro centra-se em A pesquisa, o problema e a construção da operação (pp. 61-65). Aebli analisa ai em que é que a pesquisa, pelo aluno, de um verdadeiro problema dá lugar à construção da operação e em quê o problema e as questões que coloca orienta essa pesquisa e "contém um esquema antecipador" da operação intelectual a efectuar (classificar, ordenar, explicar, etc.). Quando este esquema antecipador não constitui senão um projecto global e a operação global deva diferenciar-se e estruturar-se no decurso da pesquisa, esta dá lugar a uma progressão do pensamento, com a construção de um novo esquema ultrapassando pela sua estrutura os esquemas anteriores.

O último capítulo (pp. 66-71) da Parte psicológica é consagrado à assimilação na teoria de Piaget como uma "concepção totalmente nova da apreensão da experiência" para tratar o problema da relação entre o sujeito assimilador e o objecto assimilado. Aebli remete extensamente para Piaget $(1936,1947)$ e limita-se a indicar a evolução deste processo que vai dos esquemas sensório-motores "até à análise matemática dos fenómenos e dos objectos".

\section{A aplicação da didática}

15 As análises sobre a pesquisa, o problema e a construção das operações mentais são retomados nos dois primeiros capítulos da Parte didática : A construção das operações pela pesquisa do aluno (pp. 73-80) e 0 problema como projecto de acção (pp. 81-85), no qual Aebli discute o problema como projecto de acção efectiva, prático mas também fictício. Ele introduz o que pode ser o desenrolar de uma unidade didática com pesquisa pessoal dos alunos relevando nesse caso a necessidade de que o problema seja colocado com "um máximo cuidado". Pode pensar-se aqui na noção de devolução do problema ao aluno, que mais tarde será introduzida por Guy Brousseau (1986). Aebli salienta também a 
importância dos acertos colectivos - contudo, os trabalhos em didática mostrarão mais tarde que tais acertos constituem uma particular dificuldade para o docente. Esta abordagem do estatuto da pesquisa de problema(s) constitui uma achega significativa de Aebli sobre a qual poderiam ter-se então desenvolvido as pesquisas, nomeadamente as relativas ao ensino das matemáticas.

16 A importância da dimensão colectiva introduzida na Parte psicológica tem o seu equivalente nos desenvolvimentos do último capítulo da Parte didática : A cooperação dos alunos e o "exercício operatório" (pp. 92-106). Aí, Aebli distingue primeiro dois casos extremos de problemas : aqueles cuja resolução requer a construção de uma noção ou operação nova - a discussão em comum está-lhe adaptada - e aqueles que apelam à simples aplicação de operações conhecidas a situações novas - que se prestam ao trabalho em equipas.

As secções seguintes explicitam o trabalho didáctico que deve ainda ser efectuado. A elaboração de uma nova noção ou operação a partir da pesquisa deve ser seguida de uma implementação que deve "fazer estalar os quadros rígidos de um hábito que terá podido formar-se sem consciência do aluno" e "depurar a operação e torná-la móvel". É o que Aebli designa por "exercício operatório". As condições de produtividade deste exercício operatório são, a seguir, analisadas: trabalhar a ligação entre operação directa e operação inversa (a reversibilidade operatória), estabelecer a relação das operações associativas e também a das operações e noções a distinguir : na didática psicológica trata-se, para o docente, de fazer trabalhar o sistema das operações. Enfim, a interiorização progressiva das operações deve ser organizada via representação gráfica das mesmas. A implementação das operações interiorizadas deve também ser suscitada pelo pedido de repensar a operação executada e a seguir o de a antecipar.

$\mathrm{Na}$ “ Didática Psicológica » está-se longe da ilusão dum construtivismo estrito por vezes censurado a Aebli : o sistema de actividades cognitivas pedido ao aluno pelo docente tem pleno lugar. Todavia, um ponto fraco da ligação entre psicologia e didática que Aebli propõe é a menorização do processo de acomodação, em jogo quando a aplicação dos esquemas a objectos novos arrasta a modificação daqueles. Assinala apenas de passagem a sua existência e considera que uma "psicologia didática deverá insistir sobretudo na relação de assimilação" (p. 67). Ora, numerosos objectos de ensino que serão novidade para o aluno necessitarão de uma alteração conceptual no próprio aluno, com ou sem rotura, que deverá ser organizada pelo docente. A noção subjacente de obstáculo epistemológico foi retomada de Bachelard (1938) no desenvolvimento da teoria das situações didáticas de Brousseau $(1986,2006)$ e por numerosos didactas da matemática e das ciências experimentais.

De facto, a dimensão epistemológica em jogo na didática não é introduzida enquanto tal por Aebli, ainda que uma epistemologia implícita acerca das medidas espaciais de perímetro e de superfície suporte a experiência com que ele encerra a obra.

\section{Uma experiência de implementação da didática psicológica}

20 A Parte Experimental que encerra a obra (pp.107-153) apresenta uma experiência didática conduzida pelo próprio Aebli no $6^{\circ}$ ano do ensino primário. Diz respeito ao cálculo do perímetro e da área do retângulo bem como às operações inversas. A base é a 
da comparação de lições organizadas em aulas normais segundo os princípios da "didática tradicional" ou segundo os princípios da "didática ativa", pelo mesmo docente. Os mesmos tipos de exercícios são os colocados em ambos os casos. Os efeitos são avaliados por uma comparação dos sucessos numa prova inicial e depois numa prova final (em que os alunos têm 100 minutos para resolver 30 problemas sem dificuldades aritméticas). Para um nível inicial idêntico, os alunos do grupo "moderno" que beneficiaram de uma "didática ativa " obtém mais sucesso na prova final. Os alunos dos subgrupos "inferiores" (8-21 pontos na prova inicial, mais numerosos no grupo "moderno") apesar dos seus resultados que se mantêm débeis, manifestam nitidamente menor confusão nas operações - o que traduz uma melhor distinção do caracter unidimensional do perímetro e bidimensional da superfície. Os alunos dos subgrupos "superiores" (22 a 30 pontos na prova inicial, mais numerosos no grupo "tradicional") têm a mesma qualidade (muito elevada) de respostas na prova final.

21 Aebli discute precisamente a interpretação que a experiência pode proporcionar. Salienta, em particular, que a avaliação não apanha senão "o rendimento intelectual sob a sua forma mais 'em bruto"', numa " prova incapaz de revelar as influências mais profundas do ensino" e que a experiência deste tipo de ensino foi muito curta. Responde igualmente à crítica possível sobre a duração do ensinamento de acordo com a sua didática psicológica : a investigação pelos alunos toma mais tempo e em particular as manipulações concretas. Para Aebli essas não têm valor em si próprias senão para preparar a representação interiorizada das operações e não se justificam senão para os alunos que ele qualifica de "menos dotados". Ele responde ao dilema que daí resulta relativo à organização da turma, com uma proposta de "individualização parcial".

\section{A inexistência de uma continuidade da "Didática Psicológica » na pedagogia e na didática das matemáticas na Europa francófona : algumas hipóteses}

22 As propostas teóricas e pragmáticas de Aebli não constituíram um campo fértil para a pesquisa em educação, nem no ensino das matemáticas: nunca foram discutidas a fundo, nem em relação ao que continham de produtivo, nem relativamente ao limite epistemológico precedentemente realçado. Podem adiantar-se diversas razões, algumas específicas do contexto francês. Têm a ver, segundo pensamos, com a existência de dois grandes movimentos nos anos 50, respeitantes, por um lado, ao ensino das matemáticas e, por outro, à pedagogia.

O movimento das "matemáticas modernas", com o “ colectivo Bourbaki », traduziu-se por um debate internacional sobre uma renovação do ensino das matemáticas do secundário, envolvendo matemáticos de renome. Gustave Choquet será o primeiro presidente da CIEAM (Comissão internacional para o estudo e melhoramento do ensino da matemática) formalmente criada em 1951. É significativo que dela tenham feito parte, por um lado psicólogos (entre os quais Piaget e Gonseth) e, por outro, matemáticos (entre os quais Dieudonné, Choquet, Lichnérowicz).

Em França os debates desembocarão, em 1968, na criação dos primeiros IREM (Institutos de pesquisa sobre o ensino das matemáticas) no âmbito do ensino das matemáticas na Faculdade de Ciências de Paris. Este será o terreno fértil das 
matemáticas. Uma abordagem, como a de Aebli, não apoiada numa análise dos saberes matemáticos em causa não tinha aqui lugar.

Pelo lado da pedagogia é um outro tipo de movimento epistemológico que aparecerá. Em França, o seu chefe de fila é Gaston Mialaret: após ter criado em 1946 um laboratório de psicopedagogia, participará em 1953 numa primeira reunião, por iniciativa de Robert Dottrens, de investigadores que defenderão a cientificidade do seu domínio, isto é, uma pedagogia experimental [8]. A etapa seguinte é a da separação da psicologia das novas "Ciências da educação" em três universidades. Assim, em 1967, surgirá enquanto disciplina universitária autónoma em Bordeaux, Caen e Paris, concluindo deste modo a acção de Gaston Mialare, Jean Château e Maurice Debesse.

A defesa, por Aebli, de uma didática como instrumento de uma pedagogia baseada na teoria psicológica de Piaget ia tanto mais em contra-corrente deste movimento quanto os autores centrais se situavam numa linhagem totalmente diferente (quer epistemológica, quer politicamente): a de Wallon. Em Piaget a abordagem do desenvolvimento e da construção de conhecimentos é, antes de tudo, cognitiva ; essa abordagem é em Wallon mais unitária e o papel do Outro e do social é, nela, valorizado.

Maurice Debesse creditou realmente a Aebli o ter aberto a via do estudo dos efeitos dos métodos de ensino das matemáticas, mas só a dimensão da didática como método é sublinhada (195, pp. 802-803). Antoine Léon, que integra, em 1957, a Sorbonne [ $\left.{ }^{\circ}\right]$ por iniciativa de Debesse, discutirá mais tarde "a psicologia como fundamento de qualquer acção educativa" sintetiza essa primeira obra de Aebli que "se inspira nas concepções de J. Piaget para implementar uma pedagogia em que a formação das noções é considerada como uma construção psicológica solicitando actividade investigativa e desaguando em operações móbeis, integradas em sistemas de conjunto" (Léon, 1966, p. 464) - mas cita a seguir Vinh Bang e Morf, próximos colaboradores de Piaget - para limitar o alcance da influência da psicologia no desenvolvimento da pedagogia.

Em contrapartida, na sua apologia "Pour une éducation scientifique", publicado no primeiro número da novíssima Revue Française de Pédagogie (1967), Jean Château lamenta que "a psicologia da educação se mantenha muito embrionária", sem mencionar de todo Aebli. No mesmo período não haverá qualquer referência a Aebli na obra dirigida por Mialaret "L'apprentissage des mathématiques", apesar do seu subtítulo "Essai de psychopédagogie".

29 Matemáticos que reivindicam a iniciativa epistemológica no ensino da sua disciplina, pedagogos que afirmam a sua autonomia em relação à psicologia serão também acompanhados por um psicólogo como Gréco, próximo colaborador de Piaget - que retomou o seu curso na Sorbonne - e interlocutor de Lichnérowicz [10] : "A ideia de uma pedagogia que seria uma psicologia aplicada à educação parece-me o exemplo tipo de uma aberração epistemológica [...] Sobre a natureza do saber matemático a transmitir é primordialmente o matemático que tem a sua palavra a dizer."

30 Decididamente a conjuntura, em França, não deixava, de todo, lugar a uma "Didática Psicológica ».

31 Com a constituição da didática das matemáticas em França na década seguinte as relações com a psicologia serão redesenhadas. Professor primário e depois matemático, Guy Brousseau apresenta um panorama muito claro do histórico da sua teoria, com a sua origem matemática e as suas fontes psicológicas, num artigo recente: "Des dispositifs piagétians ... aux situations didactiques" (2012). Psicólogo, tendo também 
realizado a sua tese com Piaget, Gérard Vergnaud é, com Brousseau, um dos actores da criação da comunidade da didática das matemáticas. A sua teoria dos campos conceptuais (1990), proporciona, no quadro da aprendizagem, simultaneamente o seu devido lugar aos objectos matemáticos e ao desenvolvimento do aluno - voltará a seguir ao papel central dos esquemas. Trata-se do desenrolar de uma outra história que verá também advir no virar do século uma nova articulação da didática das matemáticas com a psicologia [11] dando o seu devido lugar à atividade do aluno e à do docente. Mas Aebli e a sua "Didactique psychologique" foram - injustamente - esquecidas no debate epistemológico sobre a didática.

\section{BIBLIOGRAFIA}

Aebli, H. (1951). Didactique psychologique. Application à la didactique de la psychologie de Jean Piaget. (4ème édition 1966). Neuchâtel, CH : Delachaux \& Niestlé.

Aebli, H. (1953). Dittatica psicologica. Applicazione alla didattica della psicologia di Jean Piaget.P Firenze : Giunti Barbera.

Aebli, H. (1958). Una didáctica fundada en la psicología de Jean Piaget. Buenos Aires : Kapeluz.

Aebli, H. (1963). Psychologische Didaktik. Stuttgart, Germany : Klett.

Aebli, H. (1965). Psychologickádidaktika. Hradec Kr.lov. : PdF KU.

Aebli, H. (1966/1971). Didática psicológica : aplicação à didática da psicologia de Jean Piaget. São Paulo : Companhia editora nacional.

Aebli, H. (1973).Didactica psihologică. Bucuresti : EdituraDidactică.

Aebli, H. (1982). Dydaktyka psychologiczna. Zastosowanie psychologii Piageta do dydaktyki. Warszawa : PWN

Aebli, H. (1960). Über die geistige Entwicklung des Kindes. Habilitation. Université de Zurich. (publication 1963).

Aebli, H. (1980). A evolução mental da criança. Petrópolis : Vozes.

Aebli, H. (1961). Grundformen des Lehrens. Ein Beitrag zur psychologischen Grundlegung der Unterrichtsmethode. Stuttgart: Klett.

Aebli, H. (1965). I principi fondamentali dell'insegnamento. (Trard. Mario Chiarenza). Firenze : Universitaria Barbera.

Aebli, H. (1976) Grundformen des Lehrens. Eine Allgemeine Didaktik auf kognitionspsychologischer Grundlage (éditionlargementrevue et élargie du texte de 1961). Stuttgart : Klett.

Aebli, H. (1978). Von Piagets Entwicklungspsychologie zur Theorie der kognitiven Sozialisation. In Steiner, G. (Hrsg.), Die Psychologie des 20. Jahrhunderts. Band VII : Piaget und die Folgen (pp. 604-627). Zürich : Kindler. 
Aebli, H. (1980). Denken : Das Ordnen des Tuns. Band 1, Kognitive Aspekte der Handlungstheorie. Stuttgart: Klett-Cotta.

Aebli, H. (1981). Denken: Das Ordnen des Tuns. Band 2, Denkprozesse. Stuttgart: Klett-Cotta.

Aebli, H. (1983). Zwölf Grundformen des Lehrens. Eine Allgemeine Didaktik auf psychologischer Grundlage. Stuttgart: Klett-Cotta.

Aebli, H. (1987). Grundlagen des Lehrens (vol. 2). Stuttgart: Klett-Cotta.

Aebli, H. (1988). 12 formas basicas de enseña. Madrid : Narcea.

Aebli, H. (1991). Factores de la enseñanza que favorecen el aprendizaje autonomo(Trad. R. Lucio). Madrid : Narcea.

Bachelard, G. (1938). La formation de l'esprit scientifique. Paris : Vrin.

Brousseau, G. (1986). Théorisation des phénomènes d'enseignement des mathématiques. Thèse de Doctorat d'État es Sciences. Université de Bordeaux.

Brousseau, G. (2012). Des dispositifs piagétiens ... aux situations didactiques. Éducation et Didactique, 6(2), 103-129.

Château, J. (1967). Pour une éducation scientifique. Revue Française de Pédagogie, 1, 9-16.

Debesse, M. (1955). Les méthodes pédagogiques. In H. Piéron (Éd.), Traité de psychologie appliquée (t.4 : Formation humaine). Paris : PUF.

Léon, A. (1966). Psychologie et action éducative : la notion de psychopédagogie. L’Année Psychologique, 66(2), 461-474.

Mialaret, G. (1967). L'apprentissage des mathématiques. Essai de psycho-pédagogie. Bruxelles : Charles Dessart.

Ouvrier-Bonnaz, R. \& Lacomblez, M. (2014). Entre schème et didactique(s) : une mise en perspective historique pour penser la question des référentiels d'activité professionnelle. In $\mathrm{B}$. Prot (Éd.), Les référentiels contre l'activité. Toulouse : Octarès.

Piaget, J. (1936). La naissance de l'intelligence chez l'enfant. Neuchâtel : Delachaux et Niestlé.

Piaget, J. (1975). L'équilibration des structures cognitives. Problème central du développement. (Études d'Épistémologie Génétique XXXIII). Paris : PUF.

Vergnaud, G. (1990). La théorie des champs conceptuels. Recherches en Didactique des Mathématiques, 10(1), 133-170.

\section{NOTAS}

1. Nota do tradutor: optou-se por deixar os títulos das obras citadas na língua original das referências utilizadas pela autora.

2. Como evidencia a bibliografia de Aebli, a sua primeira obra "Didactique psychologique" foi amplamente traduzida na Europa e também na América Latina. As obras que se seguirão, sobre o desenvolvimento do pensamento da criança, sobre o ensino e a formação dos docentes, serão publicadas em alemão e jamais traduzidas para francês nem - que seja do meu conhecimento em inglês.

3. Como exceção, Michel Fabre desenvolveu a noção de "problematização" como via de ensino, em particular nas ciências com referência a Aebli cuja "didática psicológica (obra mal conhecida, pouco citada, mas que todavia elabora os principais conceitos de uma teoria das situações 
problema) poderia fazer a ponte entre uma psicologia da atividade e uma epistemologia do problema" Cf. Fabre, M., \& Musquer, A. (2009). Comment aider l'élève à problématiser ? Les inducteurs de problématisation. Les Sciences de l'Éducation, 42(3), 111-129.

4. Ensinando sucessivamente nas universidades de Zürich, $\mathrm{CH}$; Saarbrücken, RFA; Berlin, RFA ; Constanze, RFA ; Berne, $\mathrm{CH}$

5. A única referência explícita de Brousseau $(1986,2006)$ à "Didactique psychologique" será a denúncia da conceção sensualista-empirista sobre a qual acompanha Aebli.

6. Lay, W.A. (1914, 3è éd.). Der Rechunterricht auf experimentell-pädagogischer Grundlage. Leipzig.

7. Aebli faz também referência a Claparède cuja teorização é menos elaborada do que a de Dewey. Analisa brevemente a "didática disciplina mental " de Kerschensteiner e critica a sua distinção radical entre as funções práticas e as funções teóricas do saber, resultando dum dualismo profundo entre a ação e o pensamento.

8. Mialaret presidirá em 1958 à AIPELF (Association internationale de pédagogie expérimentale de langue française) que acabara de ser criada. Quanto a Dottrens, é então o diretor do Laboratoire de pédagogie expérimentale de l'Université de Genève que fundou, ao qual Aebli esteve aliás ligado.

9. A seguir à sua exclusão do INETOP devido a divergência com Piéron sobre a psicopedagogia da orientação.

10. Gréco, P. (1969). Note sur la coopération des psychologues et des enseignants dans le cadre des expériences didactiques. Bulletin de l'APMEP, 206, 27-32.

11. A abordagem instrumental de Rabardel sustenta o estudo das tecnologias no ensino das matemáticas (Artigue, Lagrange). A dupla abordagem da didática e da psicologia do desenvolvimento de Robert \& Rogalski está no cerne do estudo das práticas do docente.

\section{AUTORES}

\section{JANINE ROGALSKI}

Directeur de recherche CNRS honoraire, associée au Groupe de Recherche et d'Etude sur l'Histoire du Travail et de L'Orientation (GRESHTO), Centre de Recherche sur le Travail et le Développement (CRTD), Conservatoire National des Arts et Métiers (CNAM), 41, Rue Gay Lussac 75005, Paris, France

Janine.Rogalski@univ-paris8.fr 